\title{
Study of Site Location and Pipeline Routing for Future Natural Gas Importing Terminal Project in Morocco
}

\author{
${ }^{1}$ Mahmoud Akdi, ${ }^{2}$ Firdaous El Ghazi, ${ }^{3}$ Moulay Brahim Sedra \\ ${ }^{1}$ Simolab, Ibn Tofail University, Kenitra, Morocco, \\ ${ }^{2}$ Simolab, Ibn Tofail University, Kenitra, Morocco, \\ ${ }^{3}$ Fste, UMI Moulay Ismail University of Meknes, Morocco, \\ 1makerase@gmail.com, ²elghazi.firdaous@gmail.com,3mysedra@yahoo.fr
}

\begin{abstract}
In order to achieve sustainable supply combustible development, Morocco is projecting to invest in its first natural gas importing and storage capacity by 2030 . This future project should be designed for electric power plants and other sectors using energy. It is not worthy that up today most of the existing power plants in Morocco are depending on coal in their electricity production, this is in contrast with the recent government environmental commitments.
\end{abstract}

Therefore, the aim of this article is to develop a research analysis related to the natural gas future project by introducing the main key aspects of choosing a site location and proposing an optimum routing for pipelines based on mathematic algorithms. It is proved that the port of Jorf Lasfar is a suitable importing terminal choice for Morocco. Afterwards, a pipeline routing will be proposed given the natural gas potential consumers. Thereby, the optimum pipeline routing starting from the importing terminal and linking the furthest consuming point is estimated at $490 \mathrm{Km}$.

Keywords - Dijkstra Algorithm, Financial preview, Natural gas, Nigeria - Morocco pipeline project, Operational research, Pipeline optimum routing.

\section{INTRODUCTION}

Facing major energy challenges, Morocco is increasingly orienting its strategic decisions towards reducing the use of polluting energy based on fossil sources. The global economic context presents significant development opportunities of Liquid Natural Gas (LNG) becoming an accessible energy source that is environment friendly and less expensive than other fuel-based or coal-based energies with a more important calorific value [1].

This global context presents a long-term opportunity for Morocco to develop electricity production and heavy industry plants that currently run on other polluting fuels. Therefore, Morocco has set itself the goal of achieving the first LNG import and storage terminal in the Kingdom. The Ministry of Energy, Mines and Sustainable Development has confirmed the future investment, the import terminal should be designed to equip Morocco with the capacity to import, store and supply natural gas to the Gas To Power (GTP) and Gas To Industry (GTI) [2] sectors covered by this program.

Therefore, this article aims to develop a scientific approach for:

- Identification and choice of the importing site through a scoring system based on factual criteria;

- As part of the future Nigeria - Morocco pipeline project, proposal of the optimal routing based on the Dijkstra Algorithm;

- Tentative of a financial preview analysis.

This article deals with a current topic of natural gas development opportunities in Morocco, the analysis conclusion can significantly contribute to a decision making regarding the choice of the new LNG importing terminal location and the pipeline routing. The introduction of natural gas can definitely reduce the use of other polluting energy sources in the kingdom.

\section{CHOICE OF LNG IMPORTING SITE LOCATION}

For any investment project, the selection of the site location weighs heavily in the investment decision in the importing terminal. Choosing the best site location can significantly impact the profitability of a project and its future development. At the present time, there are three potential site locations choices that can host the LNG import terminal project, these sites are:

- Jorf Lasfar port site

- Kenitra port site «As Is »

- Kenitra new port « To Be » 
A benchmark of the three sites is achieved below based on factual criteria. Afterwards, a comparison of the three sites is summarized through a scoring system considering the features of each site location [4].

\section{Benchmark of the Potential Site Locations}

A. Jorf Lasfar (Location: $33^{\circ} 7^{\prime} N-8^{\circ} 38^{\prime} \mathrm{O}$ )

The port of Jorf Lasfar was built in 1975 to basically export raw phosphate produced by the Cherifian Office of Phosphate (OCP) industrial group. The development of the industrial area has contributed to the development of the port and gradually supply the petrochemical companies as well. In 2011, an extension of the port was carried out to ensure the reception of oil tankers and phosphatic products.

The port of Jorf Lasfar is served via the A1 highway and the regional road R306, as well as the national road N1 from El Jadida and from Safi via R316. A freight railroad line is also connected to the port. Jorf Lasfar is considered one of the most important ports in Morocco, its capacity is expending to handle more traffic in the future. The evolution of the ports traffic is represented in Figure 1.

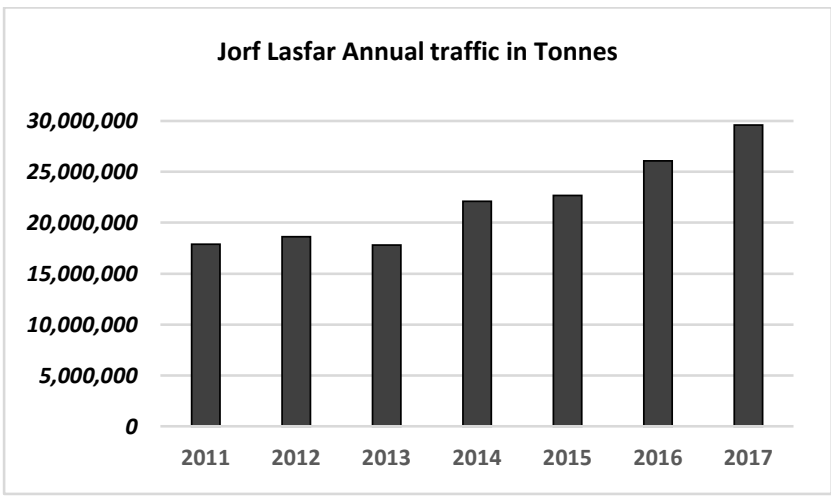

Fig .1 Jorf Lasfar port traffic evolution [3].

Figure 1 shows that the port ensures the reception of oil tankers and phosphatic products up to 30000000 tonnes in 2017.

As for the Jorf Lasfar port connectivity, the researchers present in Figure 2 a full description of the existing facilities.

The design of Jorf Lasfar port and the diversity of products crossing through have enhanced this port expertise in the reception of large cargoes. This site has several more advantages, including:

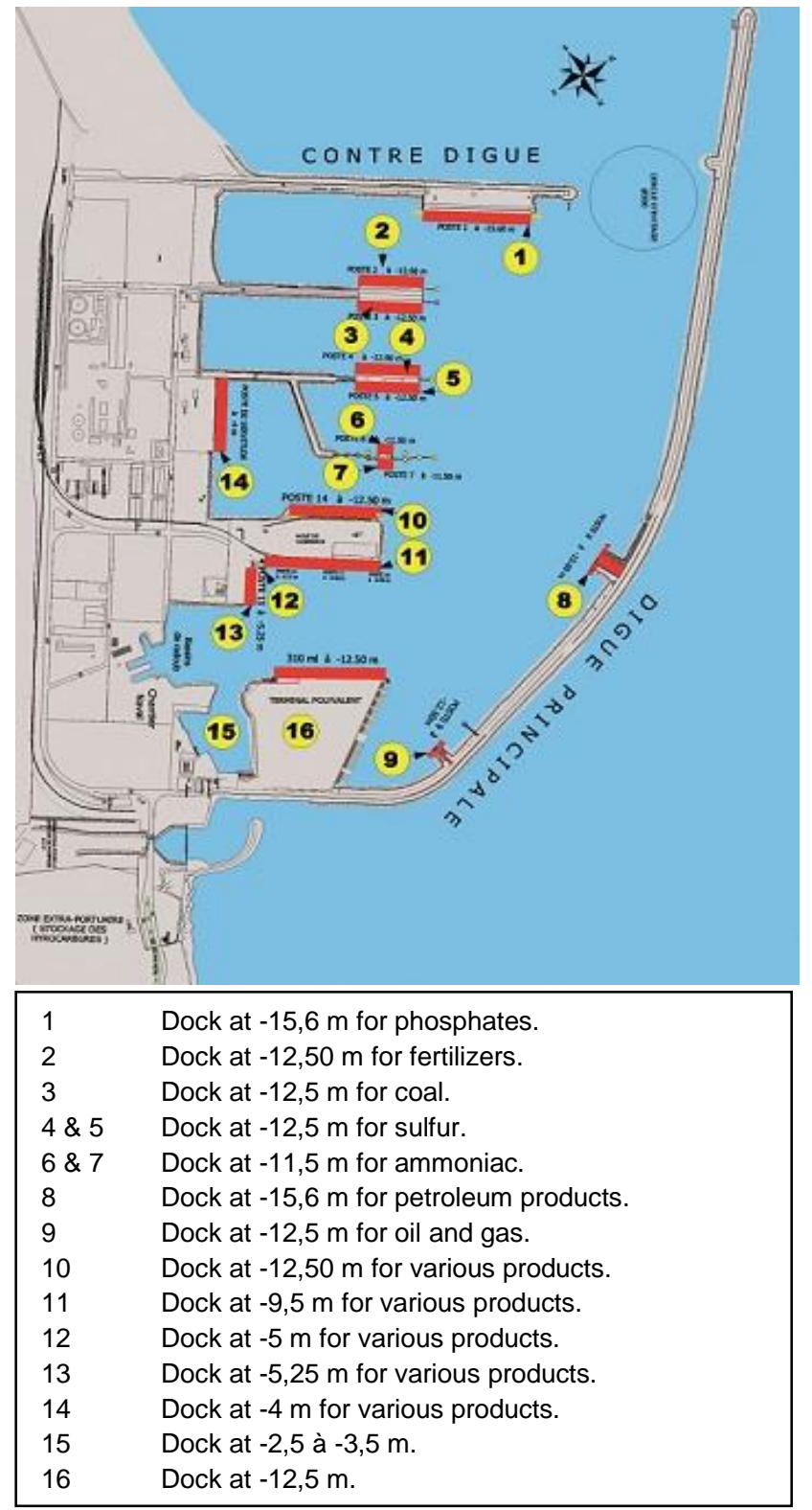

Fig .2 Jorf Lasfar port caracteristics and connectivity.

- Access to the sea with a minimum water depth of $12 \mathrm{~m}$ at low tide for large transport vessels;

- Appropriate surface conditions for the development and extension installation that can accommodate other products;

- Proximity from power plants Jorf Lasfar Energy Company (JLEC) unit 1-2, unit 3-4 and unit 5-6 and OCP power plants;

- Possibility of installing the required LNG landing dock near the actual terminal site;

- Reasonable distance to install the LNG transfer lines from the unloading dock to the LNG storage tanks. 


\section{B. Kenitra "As Is" (Location: $34^{\circ} 16^{\prime} \mathrm{N}-006^{\circ} 41^{\prime} \mathrm{O}$ )}

The port of Kenitra was built in 1912 for political and commercial reasons by the French protectorate in order to neutralize the competitive attraction of the port of Tangier. In 1996, the National Ports Agency (NPA) carried out development works to increase the river's hydraulic power and allow larger ships to access the wharves.

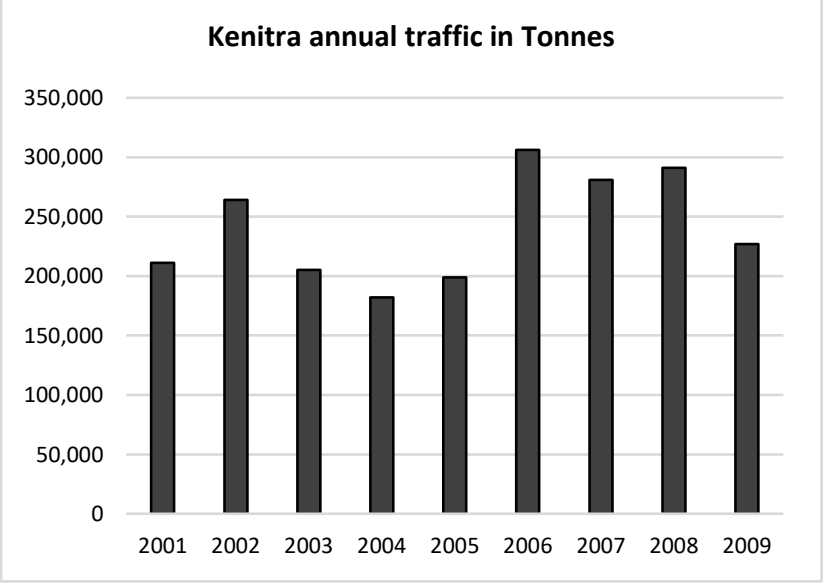

Fig .3 Kenitra port traffic evolution [3].

The evolution of traffic is represented in Figure 3.

As for the Kenitra port connectivity, the researchers present in Figure 4 a full description from the NPA official newsletter.

The current port has several limitations due to the crossing of Oued Sebbou river, the removal of the port of Kenitra to a new site nearby is being considered by the government. The new location will be the region of Oulad Bel Assal, at $24 \mathrm{~km}$ from Oued Sebou.

\section{Kenitra "As Is" (Location: $\left.34^{\circ} 16^{\prime} \mathrm{N}-006^{\circ} 41^{\prime} \mathrm{O}\right)$}

This new location of the port should bring the answers to the current limits of the Kenitra port by moving it to another location that remains nearby at $24 \mathrm{~km}$ at the north, and is even more accessible. This new port has the following advantages:

- Availability of land required for the construction of the new port (approximately $2000 \mathrm{Ha}$ ).

- Being located far away from the urban areas, this new location guarantees therefore the possibility of future extension.

Figure 5 shows the preliminary shaping of this port.

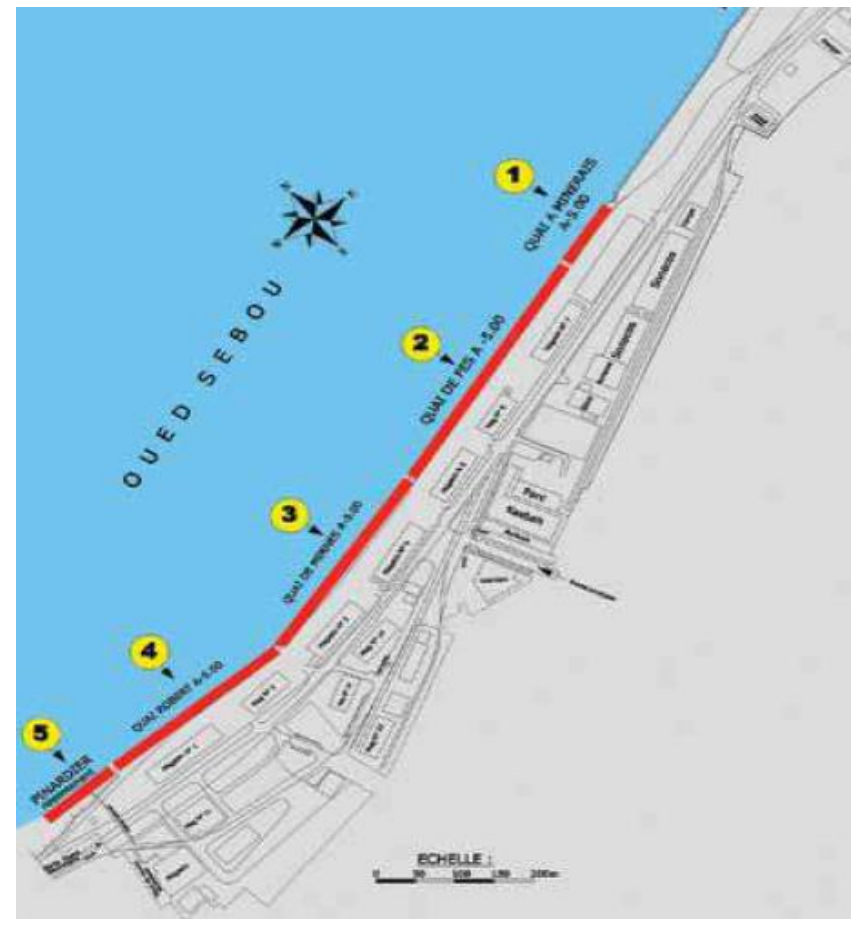

\begin{tabular}{|cl|}
\hline 1 & Dock at $-5.00 \mathrm{~m} / \mathrm{zh}$ with a length of $224 \mathrm{ml}$. \\
2 & Dock at $-5.00 \mathrm{~m} / \mathrm{zh}$; with a length of $246 \mathrm{ml}$. \\
3 & Dock at $-5.00 \mathrm{~m} /$ zh with a length of $300 \mathrm{~m}$. \\
4 & Dock at $-5.00 \mathrm{~m} /$ zh with a length of $100 \mathrm{ml}$. \\
5 & Dock at $-5.00 \mathrm{~m} /$ zh with a length of $60 \mathrm{ml}$. \\
\hline
\end{tabular}

Fig .4 Kenitra Port caracteristics and connectivity.

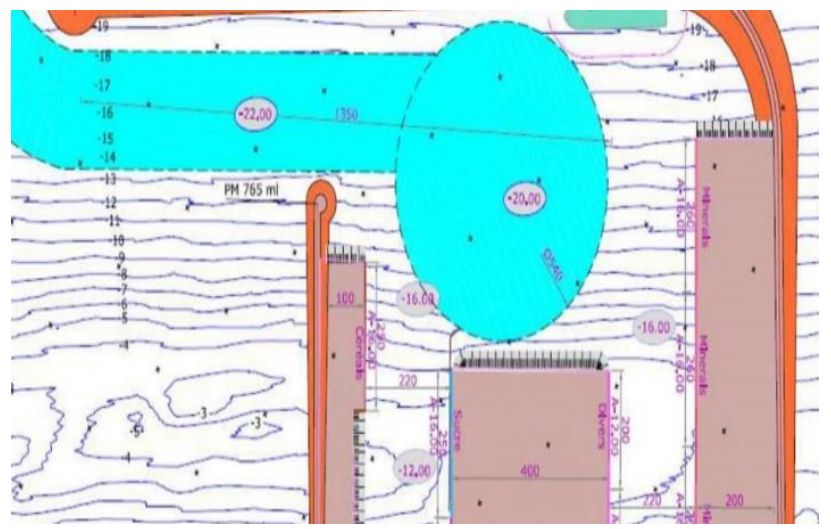

Fig .5 Evaluation study of the new Kenitra Atlantic port by Catram consulting [5].

The vocation of this new port is currently commercial as it will support the development of Kenitra city in terms of automotive industry for export as well as the reduction of traffic at Casablanca port that is already saturated.

The disadvantage remains relative to the investment required for this new port, estimated at 5 billion MAD [6]. This investment will be added to the investment required for the construction of the LNG import terminal and pipeline routing estimated at 45 billion MAD [7]. 


\section{Site Selection Criteria}

Referring to feedback from other similar LNG logistics platform projects [8], below are the main factors determining the choice of the appropriate import terminal location:

- Proximity of end use points and LNG future consumption sites;

- Proximity of the new pipeline project coming from Nigeria;

- Easy access and departure for LNG cargos,

- Distance from population areas;

- Conformity and extent of the land (available area, soil quality, geographical and topographical features, existence of groundwater tables);
- Ability to accommodate a future extension;

- Weather conditions;

- Exposure to natural hazards (earthquakes, plate tectonics, high tidal risk or potential tsunami hazards);

- Sensitivity of the surrounding environment (to be confirmed via environmental impact studies);

By using a scoring system from 1 to 5 for each criterion, the table below shows the comparison analysis between Kenitra port "As is", North Atlantic Kenitra Port (NAKP) "To Be" and Jorf Lasfar location. The ratings being:

1- Not Filled

2- Partially Filled

3- Half Filled

4- Satisfactory

Table 1. Comparison analysis between site locations.

\begin{tabular}{|c|c|c|c|c|}
\hline & 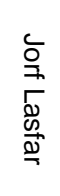 & 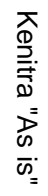 & 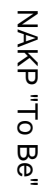 & Comments \\
\hline $\begin{array}{l}\text { Proximity of end use points and LNG } \\
\text { consumption sites }\end{array}$ & 3 & 4 & 4 & $\begin{array}{c}\text { - The main consumption points are located in North West Morocco } \\
\text { - The significant industrial areas remain half path between different } \\
\text { ports. }\end{array}$ \\
\hline $\begin{array}{l}\text { Proximity of the new pipeline project } \\
\text { coming from Nigeria }\end{array}$ & 5 & 4 & 4 & $\begin{array}{l}\text { The situation of the port of Jorf Lasfar further south allows more } \\
\text { proximity of connection with the future pipeline connecting Nigeria to } \\
\text { Morocco. }\end{array}$ \\
\hline $\begin{array}{l}\text { Easy access and departure for LNG } \\
\text { cargos }\end{array}$ & 5 & 1 & 4 & $\begin{array}{c}\text { - The present port "As Is" of Kenitra has a difficult access for large } \\
\text { boats, because of the passage by a parcel of Sebou river, additional } \\
\text { investments are needed for site redevelopment. } \\
\text { - The ease of access to the NAKP port is to be confirmed }\end{array}$ \\
\hline $\begin{array}{l}\text { Security distance available away from } \\
\text { population areas }\end{array}$ & 5 & 1 & 5 & $\begin{array}{c}\text { - The Jorf Lasfar area is classified an industrial area to be and located } \\
\text { outside the urban perimeter. } \\
\text { - Same as for the NAKP port "To Be" }\end{array}$ \\
\hline Conformity and extent of the land & 5 & 2 & 5 & $\begin{array}{c}\text { - Only the port of Kenitra "As Is" is limited in terms of possibility of } \\
\text { extension. }\end{array}$ \\
\hline $\begin{array}{l}\text { Ability to accommodate a future } \\
\text { extension }\end{array}$ & 2 & 1 & 5 & - Availability of land in NAKP port "To Be" is estimated at $2000 \mathrm{Ha}$. \\
\hline Weather conditions & 5 & 5 & 5 & The weather is favorable in all locations. \\
\hline Exposure to natural hazards & 4 & 5 & 4 & Unlikely risk, close exposure level for all location. \\
\hline $\begin{array}{l}\text { New investments necessary to } \\
\text { accomodate the port site }\end{array}$ & 5 & 4 & 1 & $\begin{array}{l}\text { - The new NAKP port "To Be" is in its study phase, the planned } \\
\text { investment is } 5 \text { billion MAD. } \\
\text { - Kenitra port "As Is" requires investment to allow LNG cargoes to pass } \\
\text { through. } \\
\text { - Only the port of Jorf Lasfar is currently adapted and ready to receive } \\
\text { an import terminal. }\end{array}$ \\
\hline Final Scoring & 39 & 27 & 37 & \\
\hline
\end{tabular}

Jorf Lasfar port and NAKP "To Be" locations have the best yet close final scoring.
Figure 6 represents the comparison result between the three possible locations. 


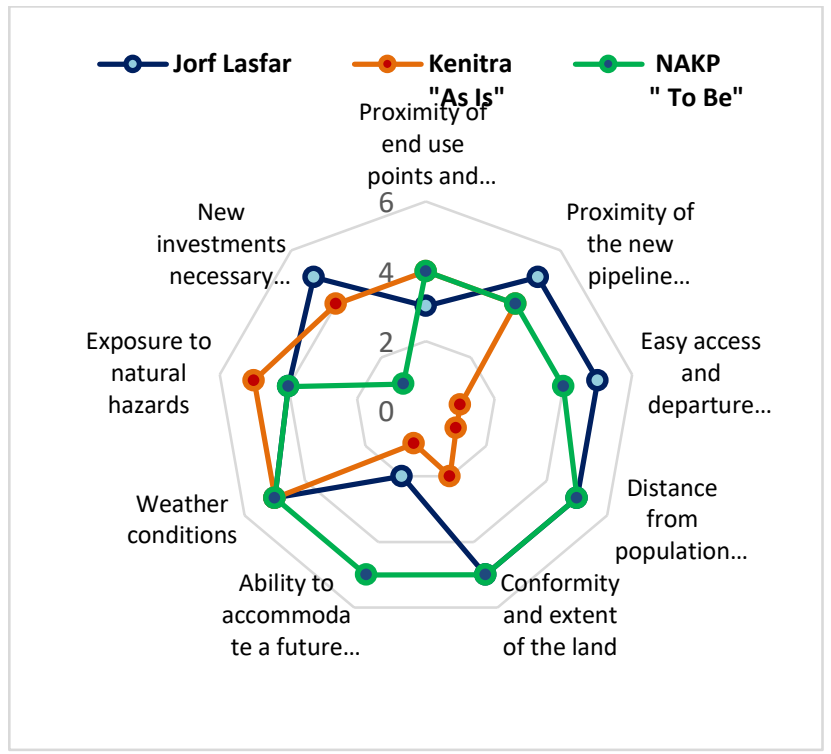

Fig .6 Final scoring of each potential site choice.

In general, since it is difficult to meet all the optimal conditions on a single location, some requirements can be reached by making changes on site at a relatively acceptable cost, the feedback from several similar projects indicates that the key variable that is likely to be discriminatory is the depth of the maritime jetty: if the depth of the water is not sufficient, the cost of carrying out development work increases and several technical constraints of reception process will be considered.

After careful considerations, the Jorf Lasfar location and the NKAP "To Be" seem both to be suitable locations for the future LNG terminal. These two locations have more many advantages when compared to Kenitra "As Is" location. However, Jorf Lasfar location, being already an existing operating port, and the NPKA" To Be" being a future port requiring an important construction budget, it is more cautious to select the Jorf Lasfar location if no further new data are revealed in the future.

The Jorf Lasfar site presents the favorable geographic location and it the best location that meets the selection criteria. It represents the least expensive site in terms of new redevelopment investments and represents fewer uncertainties in terms of costs and deadlines. This port will have the capacity to meet the national LNG import need for seizing future development opportunities.

\section{PIPELINE OPTIMUM ROUTING}

\section{LNG Future Consumers}

The import terminal project is intended to meet the needs of the country regarding LNG energy needed for the GTP and GTI programs. The investment in pipeline routing is equally important as the investment in the terminal construction itself.

It's clear that finding the optimum pipeline routing shall improve the profitability of this investment project. The first step is to find out the different consuming points and their locations, then classify the planned connection points for the pipeline as follows.

\section{A. Electricity power plants}

The power plants concerned, also called Combined Cycle Gas Turbine (CCGT), will have a percentage of electricity to be produced from natural gas. In order to do so, investments are planned to adapt the existing production facilities.

The power plants concerned are listed below [9].

Table 2. Power plants locations.

\begin{tabular}{|l|l|l|}
\hline Power plant name & City/Region & Capacity in MW \\
\hline CCGT Kenitra & Kenitra & $450 \mathrm{MW}$ \\
\hline CCGT Mohammedia & Mohammedia & $450 \mathrm{MW}$ \\
\hline AL Wahda & Sidi Kacem city & $2 \times 600 \mathrm{MW}$ \\
\hline Dhar Doum & $\begin{array}{l}120 \mathrm{~km} \text { south to } \\
\text { Tangier }\end{array}$ & $2 \times 600 \mathrm{MW}$ \\
\hline Oued Al Makhazine & $\begin{array}{l}100 \mathrm{~km} \text { south to } \\
\text { Tangier }\end{array}$ & $2 \times 600 \mathrm{MW}$ \\
\hline Tahhadart & Tahhadart Region & $\mathrm{MW}$ \\
\hline
\end{tabular}

\section{B. Industrial areas and natural gas discovered} basins

The pipeline routing should be able to cross a large industrial area, known to be host to many energy consuming industries, such as the ceramics industry and other heavy industries located in Casablanca Settat Industrial area.

On the other hand, there are two natural gas discovered basins: the underground basin of Sidi Yahya Lgharb and the underground basin of Tendrara. It's preferable that the natural gas pipeline shall be able to cross the discovered natural gas basins.

\section{Existing and future $L N G$ pipelines}

The pipeline routing should be able to cross a large industrial area, known to be host to many energy consuming industries, such as the ceramics industry and other heavy industries located in Casablanca Settat Industrial area. 

http://dx.doi.org/10.21622/RESD.2019.05.1.033

- Existing Gazoduc Maghreb Europe (GME) pipeline: It is the Maghreb Europe Pipeline, which starts from Algeria, goes through northern Morocco, crosses the Gibraltar and joins Spain. Its diameter is 48 inches, its total length is $1300 \mathrm{~km}$, including $45 \mathrm{~km}$ offshore and $540 \mathrm{~km}$ onshore on Moroccan soil.

- Future Nigeria - Morocco pipeline: This megaproject is part of a development policy in Africa, a cooperation agreement was signed between Nigeria and Morocco in December 2016. Currently, the study of this project is in FEED (Frond END and Engineering Design) phase [10]. For Several economic and political reasons, the routing of the pipeline will be operated on a combined onshore / offshore routing, the estimated length of the pipeline will be about $5.700 \mathrm{~km}$. It should be noted that investment estimates are still being revised by engineering studies. The pipeline routing can be settled after signing and negotiating access rights. Currently, this pipeline will serve many countries such as Benin, Togo, Ghana, Liberia, Sierra Leone, Guinea, Guinea Bissau, Gambia, Senegal and Mauritania before arriving to Morocco.

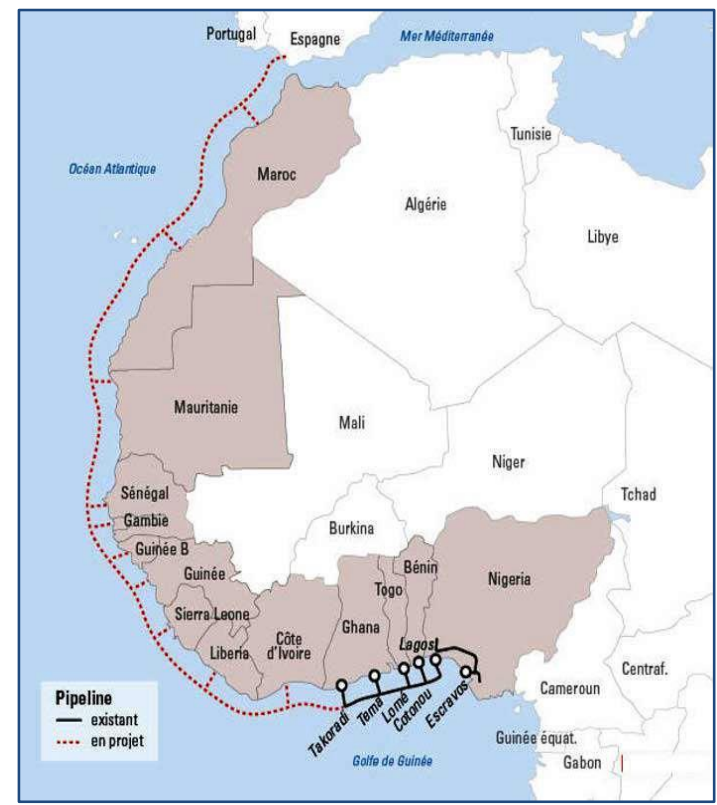

Fig .7 Planned pipeline routing, from the official website Lesinfos.ma.

In summary, the optimal pipeline routing shall be carefully designed to best meet consumption expectations, this pipeline must meet the following requirements:

- Being carried out in the continuity of the pipeline from Nigeria, this pipeline will arrive to Morocco through several countries in northwestern Africa and passing through Senegal.

- Powering the combined cycle power plants concerned by the GTP investment plan.

- Meeting the GTI need via a passage through the most important industrial area.

- The pipeline routing should take the shortest possible distance.

- The Optimum routing shall confirm the best choice of the new importing terminal.

This is an optimization problematic of the pipeline routing. The researchers present their input data and working assumptions in the form of a short-run operational search problem, Dijkstra algorithm is suitable to solve it.

\section{Dijkstra Algorithm}

Dijkstra algorithm [11] is known to be one of the most effective operational search algorithms for tracing the shortest path between multiple two distant starting and arriving points, including many intermediary possible stops and constraints. Also called graph theory, this algorithm was invented by the Dutch researcher Edsger Dijkstra in 1959. Among the most common applications of this algorithm are the telecommunications networks and the supply chain traffic.

The principle is to express the problem in the form of a graph with nodes that symbolize the intermediate stopping points, the edges symbolize the path in $\mathrm{km}$ between two successive nodes.

We note the graph $G=\{N$; Uij $\}$

We classify the nodes into 5 categories as follows:

Table 3. Nodes classification.

\begin{tabular}{|l|l|}
\hline \multicolumn{2}{|l|}{ Departure node } \\
\hline$\alpha$ & Nigeria \\
\hline Intermediary node \\
\hline$\beta$ & Senegal \\
\hline Possible locations for LNG terminal \\
\hline X & Jorf Lasfar \\
\hline Y & NAKP "To Be" \\
\hline Power stations crossing points \\
\hline A & Mohammedia Power Station \\
\hline B & Kenitra Power Station \\
\hline C & Al Wahda Power Station \\
\hline D & Dhar Doum Power Station \\
\hline E & Oued Al Makhazine Power Station \\
\hline F & Tahhadart Power Station \\
\hline
\end{tabular}




\begin{tabular}{|l|l|}
\hline \multicolumn{2}{|l|}{ Other crossing points } \\
\hline A & Casablanca - Settat Industrial Zone \\
\hline B & Underground basin of Sidi Yahya Lgharb \\
\hline C & Gazoduc Maghreb Europe \\
\hline D & Underground basin of TENDRARA \\
\hline
\end{tabular}

Therefore, our Dijkstra graph is composed of 14 nodes:

$$
\boldsymbol{N}=\{\boldsymbol{\alpha} ; \boldsymbol{\beta} ; \boldsymbol{X} ; \boldsymbol{Y} ; \boldsymbol{A} ; \boldsymbol{B} ; \boldsymbol{C} ; \boldsymbol{D} ; \boldsymbol{E} ; \boldsymbol{F} ; \boldsymbol{a} ; \boldsymbol{b} ; \boldsymbol{C} ; \boldsymbol{d}\}
$$

The researchers consider the following assumptions:

- The pipeline routing from the import terminal should be linked with the pipeline coming from Nigeria.

- The graph will contain two possible nodes for the import terminal, the algorithm will define the most ideal location to respect the shortest pipeline path.

- In terms of LNG consumption points, only CCGT power plants included in the GTP investment program are considered the most important crossing points.

- the underground natural gas basins are optional crossing points since the main natural gas resource will be imported by the future LNG terminal.

$\mathrm{U}(\mathrm{i} ; \mathrm{j})$ represents the set of distances between two nodes $\mathrm{i}$ and $\mathrm{j}$; therefore:

$$
\begin{gathered}
\left\{\begin{array}{l}
\mathrm{U}(\alpha ; \beta)=4000 \mathrm{~km} \\
\mathrm{U}(\beta ; X)=2400 \mathrm{~km} \\
\mathrm{U}(\beta ; Y)=2700 \mathrm{~km}
\end{array}\right. \\
\left\{\begin{array}{l}
\mathrm{U}(\mathrm{X} ; \mathrm{a})=114 \mathrm{~km} \\
\mathrm{U}(\mathrm{Y} ; \mathrm{a})=120 \mathrm{~km} \\
\mathrm{U}(\mathrm{Y} ; \mathrm{B})=15 \mathrm{~km}
\end{array}\right. \\
\left\{\begin{array}{l}
\mathrm{U}(\mathrm{a} ; \mathrm{B})=115 \mathrm{~km} \\
\mathrm{U}(\mathrm{B} ; \mathrm{b})=30 \mathrm{~km} \\
\mathrm{U}(\mathrm{a} ; \mathrm{b})=140 \mathrm{~km}
\end{array}\right. \\
\left\{\begin{array}{l}
\mathrm{U}(\mathrm{X} ; \mathrm{A} ; \mathrm{A})=130 \mathrm{~km} \\
\mathrm{U}(\mathrm{b} ; \mathrm{C})=60 \mathrm{~km}
\end{array}\right. \\
\left\{\begin{array}{l}
\mathrm{U}(\mathrm{b} ; \mathrm{D})=90 \mathrm{~km} \\
\mathrm{U}(\mathrm{C} ; \mathrm{D})=70 \mathrm{~km} \\
\mathrm{U}(\mathrm{D} ; \mathrm{c})=5 \mathrm{~km}
\end{array}\right. \\
\left\{\begin{array}{l}
\mathrm{U}(\mathrm{c} ; \mathrm{d})=110 \mathrm{~km} \\
\mathrm{U}(\mathrm{D} ; \mathrm{E})=70 \mathrm{~km}
\end{array}\right. \\
\left\{\begin{array}{l}
\mathrm{U}(\mathrm{E} ; \mathrm{F})=30 \mathrm{~km} \\
\mathrm{U}(\mathrm{C} ; \mathrm{D})=70 \mathrm{~km}
\end{array}\right.
\end{gathered}
$$

The distances are calculated between the nodes based on the Global Positioning System (GPS) geolocation on the map. The indicated distances do not consider some potential disturbance factors such as soil surveys, driving constraints or natural obstacles that may arise to deflect the proposed routing.

The problematic is represented in a graphic form in Figure 8 , the nodes represent the potential crossing points of passage of LNG consumption, they are connected by arcs with the distance in $\mathrm{km}$ between the nodes.

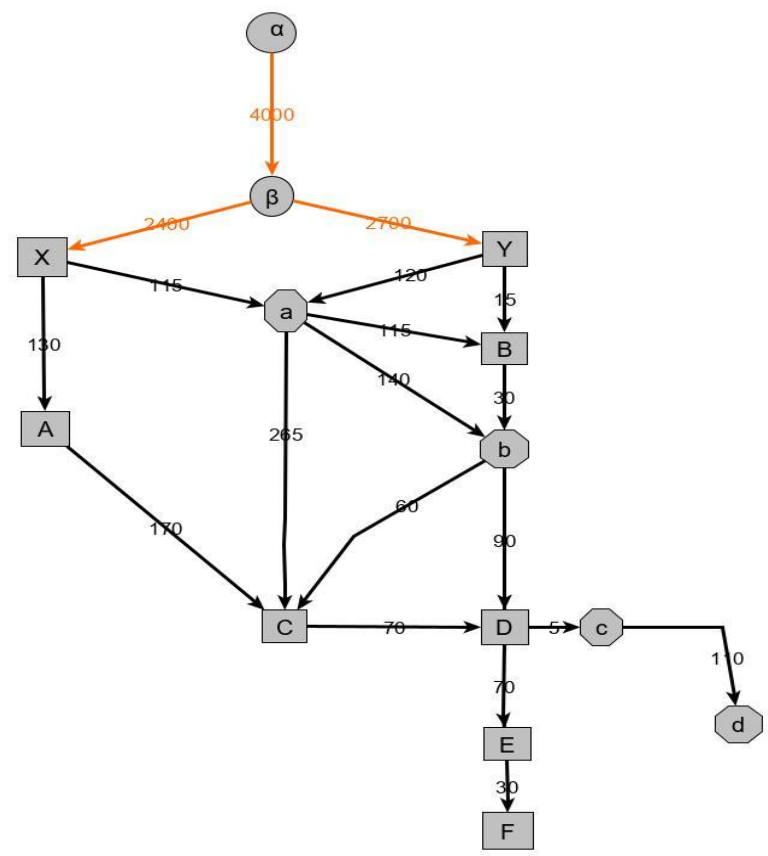

Fig .8 Dijkstra graphic representation.

$\mathrm{U}(\mathrm{i}, \mathrm{j})$ is the distance of the arc from $\mathrm{i}$ to $\mathrm{j}$.

Starting from the top node $\alpha, D$ [i] the distance of the shortest path found at a given step.

$\mathrm{E}$ is the set of nodes of passage composing the shortest definitive path. At first, E contains only the first node $\alpha$, in each step, the next node is added to $E$ and the distance $D[i]$ is updated.

Therefore, our Dijkstra algorithm can be expressed by the following function:

$$
E=\{\alpha\}
$$

For each node $\neq \alpha$, the researchers consider the following:

$$
D[i]=U[\alpha ; i]
$$


The researchers consider $t \in E$ if $\mathrm{D}[\mathrm{t}]$ the minimum possible distance, then $\mathrm{Et}=\mathrm{EU}\{\mathrm{t}\}$;

For each:

$$
i=[\beta ; X ; Y ; A ; B ; C ; D ; E ; F ; a ; b ; c ; d]
$$

$i$ is successor passage node to $t$ if:

$$
[D(t)+U(t ; i)]<D(i)
$$

Then, (3) $D(i)=D(t)+U(t ; i)$ and $i \in E$

\section{If not $i \notin E$}

Therefore, the representation of the Dijkstra algorithm is as follows:

$$
\begin{aligned}
& \left(\begin{array}{ccccc}
S T E P & \alpha & \beta & X & Y \\
1 & 0 & 4000 \alpha & & \\
2 & \chi & 4000 \not \alpha & 4600 \beta & 6700 \beta \\
3 & \chi & \chi & 4600 \beta & \\
4 & \chi & \chi & \chi & \\
5 & \chi & \chi & \chi & \\
6 & \chi & \chi & \chi & \\
7 & \chi & \chi & \chi & \\
8 & \chi & \chi & \chi & 6700 \beta \\
9 & \chi & \chi & \chi & \chi \\
10 & \chi & \chi & \chi & \chi \\
11 & \chi & \chi & \chi & \chi \\
12 & \chi & \chi & \chi & \chi \\
13 & \chi & \chi & \chi & \chi
\end{array}\right) \\
& \left(\begin{array}{ccccccc}
\text { STEP } & A & B & C & D & E & F \\
1 & & & & & & \\
2 & & & & & & \\
3 & 6530 X & \multicolumn{7}{c}{} & & & \\
4 & \multicolumn{7}{c}{6630 a} & 6780 a & & & \\
5 & 6530 / X & 6700 A & & & \\
6 & \chi & 6630 / a & & & & \\
7 & \chi & \chi & 6720 b & 6750 b & & \\
8 & \chi & \chi & 6720 / b & 6790 C & & \\
9 & \chi & \chi & \chi & 6790 / C & 68600 & \\
10 & \chi & \chi & \chi & \chi & & \\
11 & \chi & \chi & \chi & \chi & & \\
12 & \chi & \chi & \chi & \chi & 6860 / D & 6890 E \\
13 & \chi & \chi & \chi & \chi & \chi & 6890 / \mathrm{E}
\end{array}\right)
\end{aligned}
$$

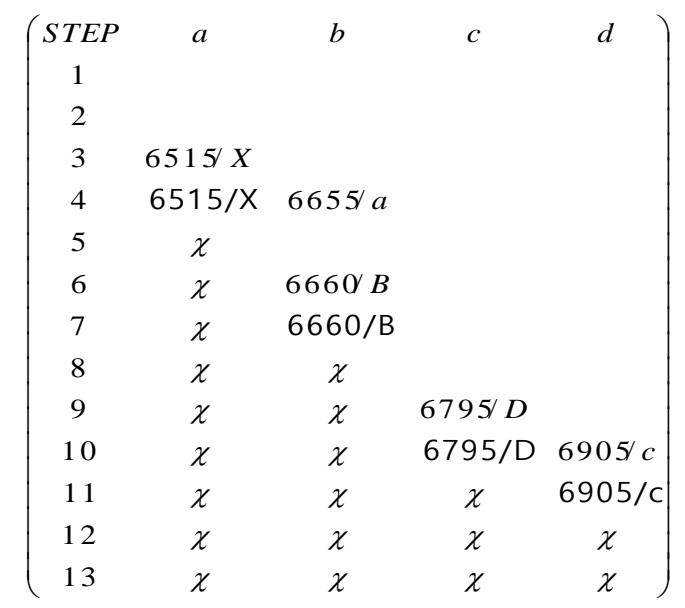

The interpretation of the result is done by following the step numbers and the nodes in bold and corresponding distances indicate the optimum routing.

\begin{tabular}{|c|c|c|l|}
\multicolumn{5}{|c|}{ Table 4. Optimum routing steps. } \\
\hline Step & $\mathrm{t}$ & $\mathrm{D}(\mathrm{t})$ & $\mathrm{E}$ \\
\hline 1 & $\alpha$ & 0 & $\{\alpha\}$ \\
\hline 2 & $\beta$ & 4000 & $\{\alpha ; \beta\}$ \\
\hline 3 & $\mathrm{X}$ & 6400 & $\{\alpha ; \beta ; \mathrm{X}\}$ \\
\hline 4 & $\mathrm{a}$ & 6515 & $\{\alpha ; \beta ; \mathrm{X} ; \mathrm{a}\}$ \\
\hline 5 & $\mathrm{~B}$ & 6630 & $\{\alpha ; \beta ; \mathrm{X} ; \mathrm{a} ; \mathrm{B}\}$ \\
\hline 6 & $\mathrm{~b}$ & 6660 & $\{\alpha ; \beta ; \mathrm{X} ; \mathrm{a} ; \mathrm{B} ; \mathrm{b}\}$ \\
\hline 7 & $\mathrm{C}$ & 6720 & $\{\alpha ; \beta ; \mathrm{X} ; \mathrm{a} ; \mathrm{B} ; \mathrm{b} ; \mathrm{C}\}$ \\
\hline 8 & $\mathrm{D}$ & 6790 & $\{\alpha ; \beta ; \mathrm{X} ; \mathrm{a} ; \mathrm{B} ; \mathrm{b} ; \mathrm{C} ; \mathrm{D}\}$ \\
\hline 9 & $\mathrm{E}$ & 6860 & $\{\alpha ; \beta ; \mathrm{X} ; \mathrm{a} ; \mathrm{B} ; \mathrm{b} ; \mathrm{C} ; \mathrm{D} ; \mathrm{E}\}$ \\
\hline 10 & $\mathrm{~F}$ & 6890 & $\{\alpha ; \beta ; \mathrm{X} ; \mathrm{a} ; \mathrm{B} ; \mathrm{b} ; \mathrm{C} ; \mathrm{D} ; \mathrm{E} ; \mathrm{F}\}$ \\
\hline
\end{tabular}

The optimum distance from point $\alpha$ (Nigeria) to point $F$ (Tahhadart power station) is $6890 \mathrm{~km}$.

Given the $6400 \mathrm{~km}$ between Nigeria and Jorf Lasfar, the shortest distance from Jorf Lasfar to power station Tahhadart is $6890 \mathrm{~km}-6400 \mathrm{~km}=490 \mathrm{~km}$.

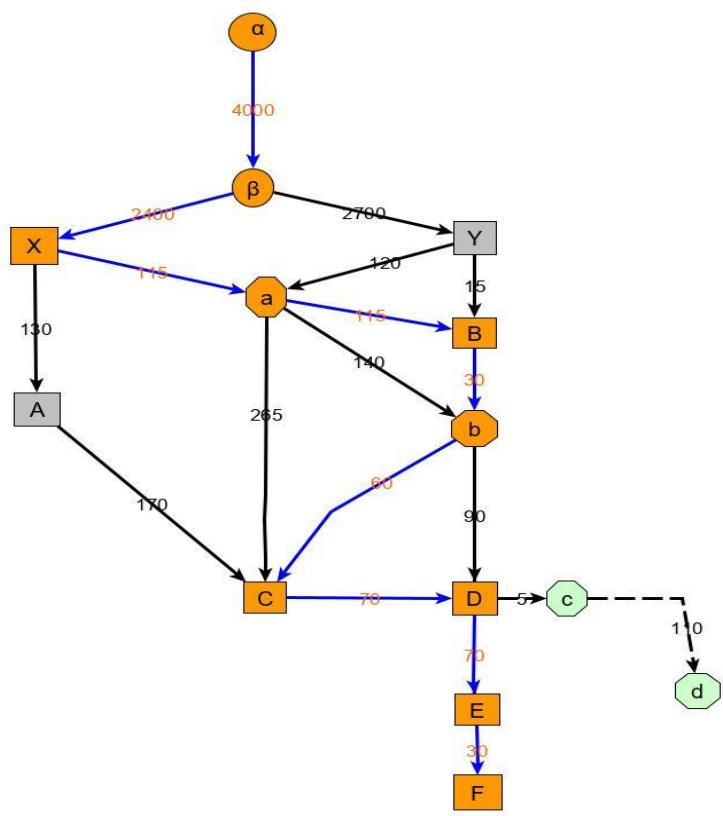

Fig .9 Dijkstra graphic solution. 
The optimal routing given by Dijkstra algorithm goes through the following nodes marked in orange in Figure 9.

\section{Results Interpretation}

The optimum routing can be described as follows:

Table 5. Optimum routing description part 1.

\begin{tabular}{|l|c|l|}
\hline \multirow{2}{*}{ Departure } & $\alpha$ & $\begin{array}{l}\text { Nigeria } \\
4000 \mathrm{~km}\end{array}$ \\
\cline { 2 - 3 } & $\beta$ & $\begin{array}{l}\text { Senegal } \\
2400 \mathrm{~km}\end{array}$ \\
\hline LNG terminal & X & $\begin{array}{l}\text { Jorf Lasfar Location } \\
115 \mathrm{~km}\end{array}$ \\
\hline Industrial area & a & $\begin{array}{l}\text { Settat - Casablanca } \\
115 \mathrm{~km}\end{array}$ \\
\hline Power station 1 & B & $\begin{array}{l}\text { Kenitra power station } \\
30 \mathrm{~km}\end{array}$ \\
\hline Undergroud basin 1 & b & $\begin{array}{l}\text { Sidi Yahya Lgharb basin } \\
60 \mathrm{~km}\end{array}$ \\
\hline Power station 2 & C & $\begin{array}{l}\text { Al wahda power station } \\
70 \mathrm{~km}\end{array}$ \\
\hline Power station 3 & D & $\begin{array}{l}\text { Dhar Doum power station } \\
70 \mathrm{~km}\end{array}$ \\
\hline Power station 4 & E & $\begin{array}{l}\text { Oued al Makhazine power station } \\
30 \mathrm{~km}\end{array}$ \\
\hline Power station 5 & F & \begin{tabular}{l} 
Tahhadart power station \\
\hline
\end{tabular} \\
\hline
\end{tabular}

A complementary routing can also be proposed to link the pipeline project with the existent GME pipeline, and then arrive to Tendrara Underground basin. Therefore, this complementary routing will be as follows:

Table 6. Optimum routing description part 2.

\begin{tabular}{|l|c|l|}
\hline Power station 3 & D & $\begin{array}{l}\text { Dhar doum } \\
5 \mathrm{~km}\end{array}$ \\
\hline GME gazoduc & C & $\begin{array}{l}\text { Gazoduc Maghreb Europe } \\
110 \mathrm{~km}\end{array}$ \\
\hline Undergroud basin 2 & d & Tendrara basin \\
\hline
\end{tabular}

This study aims to achieve two main objectives; the first is to confirm the ideal location for LNG importation terminal and the second is to propose the shortest pipeline routing between the departure point $\alpha$ representing Nigeria and the arrival point $F$ representing the Tahhadart power station.

The optimal routing is shown on the following map:

Using Dijkstra algorithm, the Jorf Lasfar site is also suggested to be a suitable choice location for the future import terminal port.

Starting the Jorf Lasfar port, the crossing points are: 5 power stations, 2 underground basins and 1 industrial area.

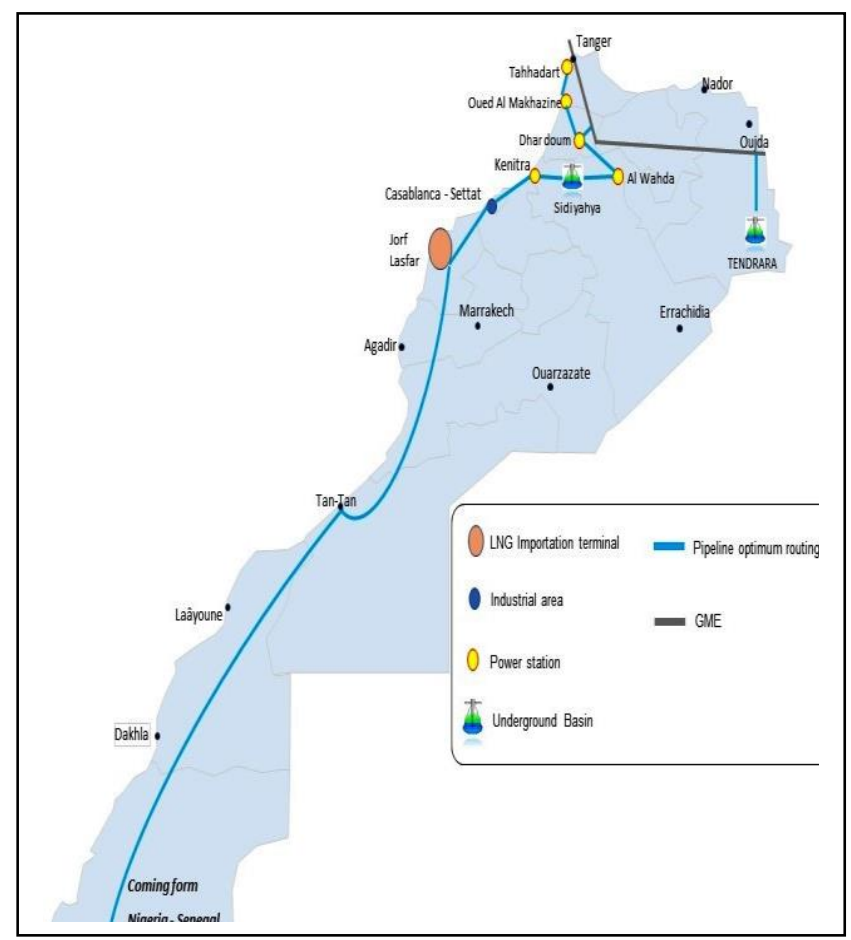

Fig .10 Optimum routing solution.

\section{FINANCIAL EVALUATION PREVIEW}

After defining the pipeline shortest routing, the cost for the future pipeline is hard to evaluate given the available data at this moment. The cost of the pipeline can weigh heavily in the amount of the project investment, its cost depends on several unknown parameters such as the type and the diameter of the pipeline, the cost of the steel, the width of the pipeline, the nature of the environment and the depth of its passage.

The investment reference announced for $5660 \mathrm{~km}$ of the Nigeria - Morocco pipeline project is estimated at 20 to 50 billion dollars [11]. Therefore, considering the same pipeline characteristics for $490 \mathrm{~km}$ portion of pipeline proposed routing, the investment can be estimated at 1,8 to 4,5 billion dollars. This investment shall cover all the performances bellow:

- Engineering studies

- Execution study (works, cathodic protection ...)

- Civil engineering work

- Pipeline works

- Installation work of compression stations

- Piping and connection work 
- $\quad$ Cathodic protection installation work

- $\quad$ Leak detection system installation work

- Pre-commissioning

- Commissioning

It's difficult to go any further in the rentabilitystudy since the international natural gas market is made up of different regional markets, making it difficult to talk about regular prices. Figure 11 can demonstrate the extreme volatility in natural gas prices.

Global gas prices, USD / MBtu

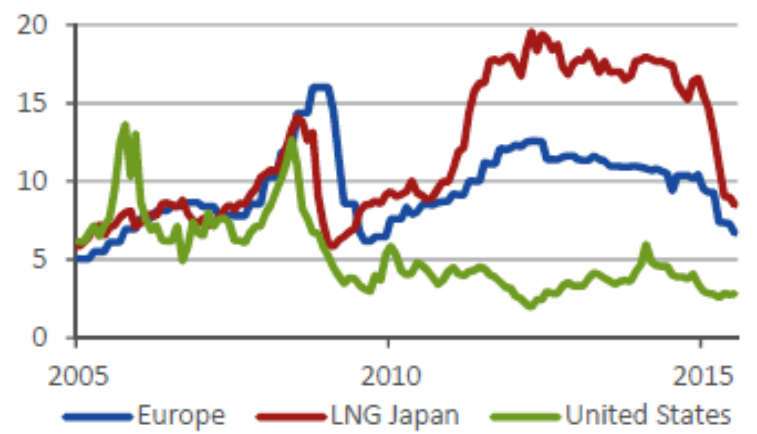

Source: IMF

Fig .11 Gas prices volatility from the International Monetary Fund official newsletter.

The correlation between the price of oil and LNG is difficult to establish as these two markets are distinct. All LNG supply contracts are governed by a start date and an expiration date. During this period, the contract specifies the quantities supplied as well as the upper and lower tolerated variation limits.

In general, the main components of the price of natural gas are:

- The gas wellhead price

- The sea freight, and

- The cost of transportation along a distance

Price is governed by the strength of supply and demand, which can lead to price fluctuations as the market loses or regains its balance. To reduce its exposure to price volatility, significant storage capacity would be required to import and store the gas when prices are low often in summer when demand is lower. Many buyers also use financial assurance systems, such as hedging.
The rentability study of this project can be another interesting aspect to develop when more financial and contractual data about the project are revealed.

\section{v. CONCLUSION}

The Kingdom of Morocco has shown a growing preference for LNG to assure energy efficiency.

Given the significant international changes in energy supply and environmental protection, the new national energy strategy is progressively ensuring its procurement of natural gas while driving the energy transition with pragmatism and anticipation. In this context, this article developed two aspects of this program:

- The choice of site location for the LNG import, storage and regasification terminal

- The shortest path for distribution and connection pipeline using the Dijkstra algorithm

The pipeline routing is an important part of the LNG project in terms of necessary investment. This routing should adapt to many constraints of passage and come in continuity of the pipeline connecting Nigeria to Morocco.

The port of Jorf Lasfar is a suitable importing terminal choice. The pipeline perimeter supported by the national LNG project is identified between the import terminal and the furthest point of consumption, the pipeline routing starting from Jorf Lasfar terminal and linking the consumption points is estimated at $490 \mathrm{~km}$.

The environmental qualities of natural gas largely justify the conduction of this project. With its high hydrogen content, gas combustion is considered perfect and does not produce heavy unburnt harmful particles for environment or health. Given the tax incentives and government conventions planned in Morocco to encourage the use of natural gas, the profitability of this investment is guaranteed on a long term.

\section{REFERENCES}

[1] R. Laplante, F. L'Italien, N. Mousseau, and S. Labranche, 2nd International Summit Of Research Cooperatives In Community Development, Energy transition, how to get out from fossil fuel UNIVERSITY OF QUEBEC, available on: http://normandmousseau.com/publications/159.p df [2015] 
[2] Amara, Ministry of Energy, Mines, Water and Environment, Roadmap of the National Development Plan forLiquefied Natural Gas. P. 11 , available on: https://fr.scribd.com/doc/250255788/PlanNational-Marocain-de-Developpement-Du-GazNaturel-Liquefie-Gnl [2014].

[3] The National Ports Agency. Available on : http://www.equipement.gov.ma/CarteRegion/RegionSafi/Patrimoine-desinfrastructures-regionales/Portsmaritimes/Pages/Fiche-Synthetique-Port-JorfLasfar.aspx [2019]

[4] The National Ports Agency. Available on: https://www.anp.org.ma/Services/Portkenitra/Pag es/Presentation.aspx [2019]

[5] CATRAM Consulting, Evaluation Study of the New Kenitra Atlantic. Available on: https://www.catram consultants.com/kenitraatlantique/ 2017

[6] Official Announcement from the Management of the National Ports Agency. Available on: http://fr.le360.ma/economie/anp-5-milliards-dedirhams-dinvestissements-au-programme111725 [2017]

[7] Ministry of Energy, Mines, Water and Environment
(2017). Draft Law Relating to the Downstream Sector of Natural Gas in Morocco. N 9417 , page 2.

[8] R. Tarakad, LNG Receiving and Regasification Terminals, an Overview of Design, Operation and Project Development Consideration, pp. 31--34, [2003].

[9] Amara, Ministry of Energy, Mines, Water and Environment, Roadmap of the National Development Plan for Liquefied Natural Gas. p. 7, available on: https://fr.scribd.com/doc/250255788/PlanNational-Marocain-de-Developpement-Du-GazNaturel-Liquefie-Gnl [2014]

[10] Benchmark of the Royal Institute of Strategic Studies , available on: https://www.medias24.com/MAROC/ECONOMIE /ECONOMIE/188546-Gazoduc-Maroc-NigeriaVoici-un-benchmark-de-I-Institut-royal-desetudes-strategiques.html [2018]

[11] N.Jasika, and N.Alispaic . "Dijkstra's shortest path algorithm serial and parallel execution performance analysis," INSPEC Accession Number: 12865637. Available on: https://ieeexplore.ieee.org/abstract/document/62 40942/figures\#figures [2012] 